\title{
Straightforward synthesis of cyclic and bicyclic peptides
}

\author{
Xavier Elduque, Enrique Pedroso and Anna Grandas* \\ Departament de Química Orgànica and IBUB, Facultat de Química, Universitat de \\ Barcelona, Martí i Franquès 1-11,08028 Barcelona, Spain
}

anna.grandas@ub.edu

Received Date (will be automatically inserted after manuscript is accepted)

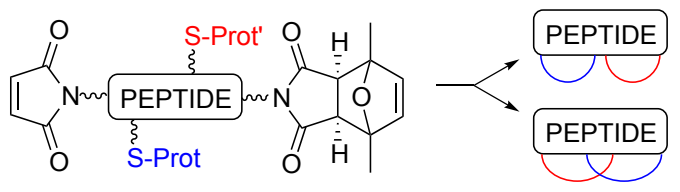

Cyclic peptide architectures can be easily synthesized from cysteine-containing peptides with appending maleimides, free or protected, through an intramolecular Michael-type reaction. After peptide assembly, the peptide can cyclize either during the trifluoroacetic acid treatment, if the maleimide is not protected, or upon deprotection of the maleimide. The combination of free and protected maleimide moieties and two orthogonally protected cysteines gives access to structurally different bicyclic peptides with isolated or fused cycles.

Cyclization has been long recognized to provide peptides with increased stability to enzymatic degradation and better cell permeability (see 1 for recent reviews). Cyclization imposes structural constraints and allows for structural preorganization of functional groups, but the degree of flexibility still permitted is expected to enhance and facilitate interaction with the receptor target. In addition to their potential role as enzyme inhibitors, cyclic peptides are considered useful tools to interrogate complex structures, and show promise to interfere with protein-protein interactions. ${ }^{1}$ Cyclic peptides can also mimic protein loops. In this respect, appending conformationally constrained peptides from a scaffold can simulate the distribution of protein loops in space, ${ }^{2}$ and this is of interest for immunological studies. In a different context, a Zinc-finger-type phosphorylated peptide with a cycle formed by metal chelation was able to distinguish between DNAs incorporating one of the two cytosines

1 (1) (a) Marsault, E.; Peterson, M. L. J. Med. Chem. 2011, 54, 19612004. (b) Madsen, C. M.; Clausen, M. H. Eur. J. Org. Chem. 2011, 3107-3115. (c) White, C. J.; Yudin, A. K. Nat. Chem. 2011, 3, 509-524.

2 (2) (a) Timmerman, P.; Beld, J.; Puijk, W. C.; Meloren, R. H. ChemBioChem 2005, 6, 821-824. (b) Heinis, C.; Rutherford, T.; Freund, S.; Winter, G. Nat. Chem. Biol. 2009, 5, 502-507. (c) Ghosh, P. S.; Hamilton, A. D. J. Am. Chem. Soc. 2012, 134, 13208-13211. involved in epigenetic regulation, namely 5hydroxymethylcytosine and 5-methylcytosine. ${ }^{3}$

Peptide macrocycles can be obtained by bridging the two ends of the peptide chain (head-to-tail), internal positions, or both. Chemical synthesis has provided the most frequently occurring natural bridges (disulfides, macrolactames, macrolactones), ${ }^{1,4}$ as well as rings with biaryls and diaryl ethers. ${ }^{5}$ Moreover, ring-closing metathesis, the $\mathrm{Cu}(\mathrm{I})$-catalyzed azide-alkyne cycloaddition, ${ }^{1,4}$ the reaction between a nucleophile and an activated pyridine-N-oxide ${ }^{6}$ and sulfur-mediated reactions ${ }^{7}$ have also afforded peptide cycles. When the latter involve a thiol and an alkene, thioether formation may take place either through radical $^{8}$ or Michael-type

${ }^{3}$ (3) Nomura, A.; Sugizaki, K.; Yanagisawa, H.; Okamoto, A. Chem. Commun. 2011, 47, 8277-8279.

${ }^{4}$ (4) (a) Jiang, S.; Li, Z.; Ding, K.; Roller, P. P. Curr. Org. Chem. 2008, 12, 1502-1542. (b) Driggers, E. M.; Hale, S. P.; Lee, J.; Terret, N. K. Nat. Rev. Drug Discov. 2008, 7, 608-624.

5 (5) (a) Pitsinos, E. N.; Vidali, V. P.; Coladouros, E. A. Eur. J. Org. Chem. 2011, 1207-1222. (b) Meyer, F.-M.; Collins, J. C.; Borin, B.; Bradow, J.; Liras, S.; Limberakis, C.; Mathiowtz, A. M.; Philippe, L.; Price, D.; Song, K.; James, K. J. Org. Chem. 2012, 77, 3099-3114.

${ }^{6}$ (6) Londregan, A. T.; Farley, K. A.; Limberakis, C.; Mullins, P. B.; Piotrowski, D. W. Org. Lett. 2012, 14, 2890-2893.

7 (7) Hoyle, C. E.; Lowe, A. B.; Bowman, C. N. Chem. Soc. Rev 2010, 39, 1355-1387.

${ }^{8}$ (8) Aimetti, A. A.; Shoemaker, R. K.; Lin, C.-C.; Anseth, K. S. Chem. Commun. 2010, 46, 4061-4063. 
Scheme 1. First syntheses of a cyclic peptide (a) and assessment of cyclization (b).

a)

a) H-Lys-Tyr-Ala-Tyr-Cys-Gly-
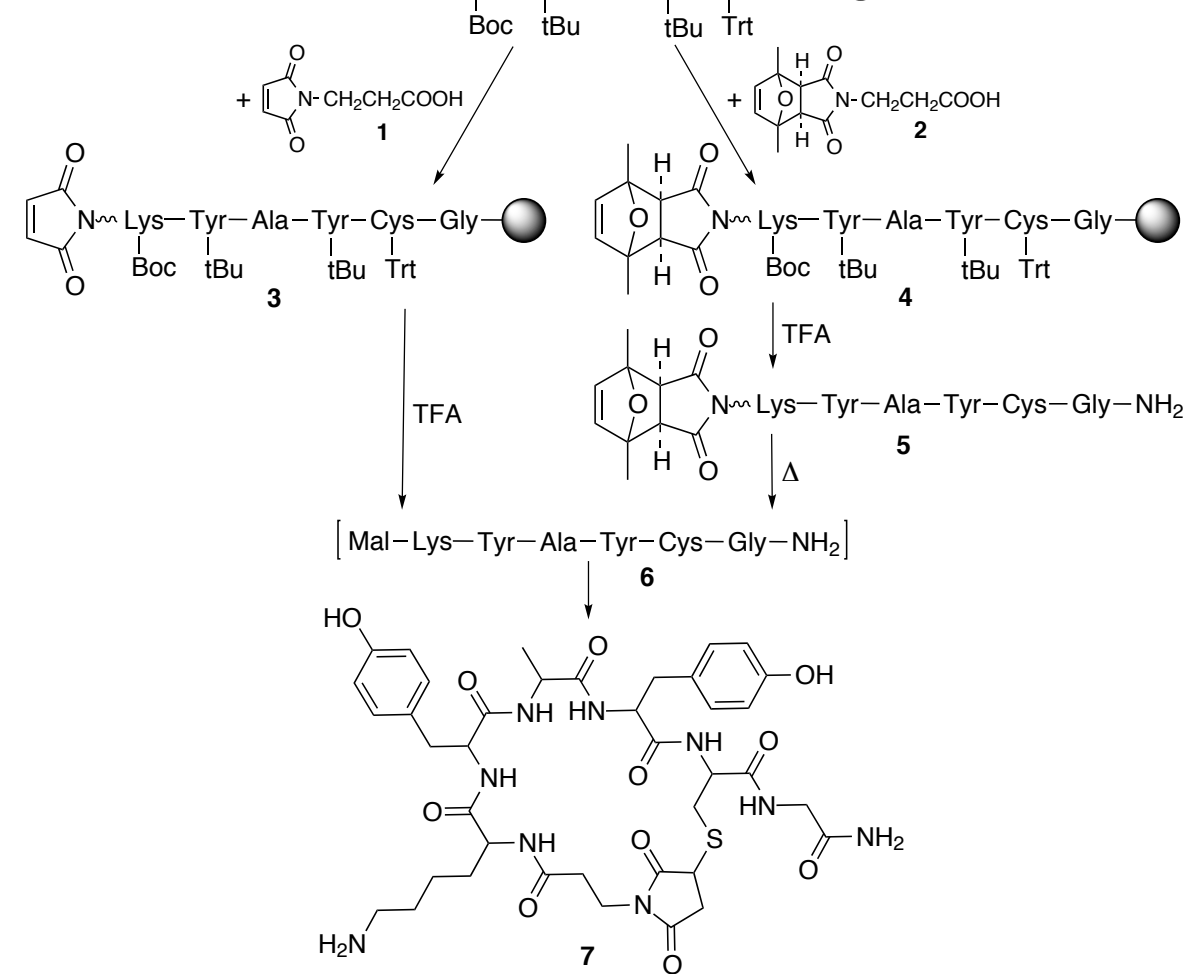

b)

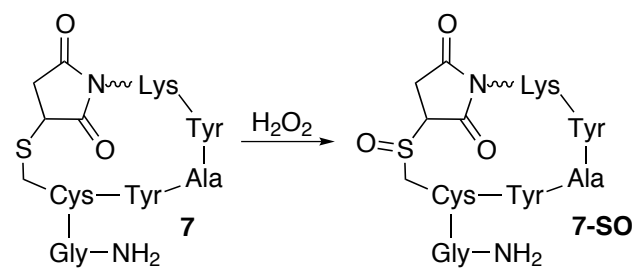

processes. ${ }^{9}$ Even though the addition of a thiol to a maleimide is one of the oldest and most extensively used "click" reactions, it has hardly ever been exploited to obtain cyclic biomolecules. ${ }^{10}$ There is one report dealing with the on-resin cyclization of a peptide incorporating an $\mathrm{N}$-terminal maleimide, ${ }^{10 \mathrm{a}}$ and a very recent one on the synthesis of cyclic oligonucleotides. ${ }^{10 \mathrm{~b}}$ In this manuscript we describe its application to the preparation of peptide monocycles and bicycles in solution.

To prove the suitability of the thiol-ene Michael reaction for this purpose, peptide sequence KYAYCG was assembled on the Rink amide resin (Scheme 1a, for

${ }^{9}$ (9) (a) Polinski, A.; Cooney, M. G.; Toy-Palmer, A.; Ösapay, G.; Goodman, M. J. Med. Chem. 1992, 35, 4185-4194. (b) Galande, A. K.; Trent, J. O.; Spatola, A. F. Biopolymers 2003, 71, 534-551. (c) Zhu, Y.; Gieselman, M. D.; Zhou, H.; Averin, O.; van der Donk, W. Org. Biomol. Chem. 2003, 1, 3304-3315. (d) Matteucci, M.; Bhalay, G.; Bradley, M. Tetrahedron Lett. 2004, 45, 1399-1401.

${ }^{10}$ ) (a) Sharma, S. K.; Wu, A. D.; Chandramouli, N. Tetrahedron Lett. 1996, 37, 5665-5668. (b) Sánchez, A.; Pedroso, E.; Grandas, A. Chem. Commun. 2013, 49, 309-311. details see Supplementary Information). Maleimides are labile to nucleophilic bases and thus not compatible with the piperidine treatments that remove the Fmoc group in standard Fmoc/tBu peptide chemistry. Hence, the maleimide moiety has to be incorporated either after the chain has been fully assembled, or during chain elongation provided that it is protected. ${ }^{11}$ For comparison purposes, part of the protected peptide-resin was derivatized with 3-maleimidopropanoic acid (1), and part with 3-[2,5-dimethylfuran protected maleimido]propanoic acid (2). ${ }^{12}$ Trifluoroacetic acid treatment of peptide-resin $\mathbf{3}$ provided a crude whose main product (Figure $\mathrm{S} 1$ ) was isolated and treated with $\mathrm{H}_{2} \mathrm{O}_{2}$ to investigate whether it was linear (6) or circular (7). Under the reaction conditions, ${ }^{12}$ the free thiol of the linear precursor (6) is oxidized to sulfonic acid (mass 48

${ }^{11}$ (11) Elduque, X.; Sánchez, A.; Sharma, K.; Pedroso, E.; Grandas, A. Bioconjugate Chem. accepted for publication.

${ }^{12}$ (12) Sánchez, A.; Pedroso, E.; Grandas, A. Org. Lett. 2011, 13, 4363-4367. 
units higher), whereas the thioether of the cyclic compound becomes a sulfoxide (mass 16 units higher). After treatment with $\mathrm{H}_{2} \mathrm{O}_{2}$ it was found that the main product in the crude was the sulfoxide of the cyclic molecule (7-SO, Scheme 1b), which showed that the Michael-type thiol-maleimide reaction can take place even in the strongly acidic deprotection medium, either during the deprotection procedure or upon elimination of the deprotecting mixture when the solution becomes more concentrated. 7 Was found to be accompanied by some cyclic dimeric and trimeric peptides (about $24 \%$ in the crude, see Figure S1).

Acidolysis (trifluoroacetic acid) of peptide-resin 4 removed permanent protecting groups on the peptide, affording [protected maleimido]-peptide 5 (Scheme 1a). The maleimide was then deprotected by heating in a microwave oven at $90{ }^{\circ} \mathrm{C}$. In agreement with previous results, ${ }^{10,11}$ the retro-Diels-Alder reaction and cyclization took place simultaneously, furnishing a thiosuccinimide that remained stable to the heating conditions.

Different peptide concentrations were tested to examine under which maleimide deprotection conditions the target monocycle $\mathbf{7}$ was exclusively formed from $\mathbf{5}$, or at least formation of 7 was favored over that of oligomers. As summarized in Table S1 (see also Figure S3), in no case was it possible to fully prevent formation of the cyclic dipeptide. Yet, in concentrations below 1 $\mathrm{mM}$ the extent of cyclic dimer formation did not exceed $5 \%$, and formation of cyclic tripeptide was virtually nil. Hence, protection of the maleimide allows for a higher control of the dilution conditions in which cyclization takes place, so that fully protected [maleimido peptide]resins such as $\mathbf{4}$ are better precursors of peptide rings than peptide-resins with a free maleimide such as $\mathbf{3}$. Moreover, the overall yield of the $\mathbf{4} \rightarrow \mathbf{7}$ process ( $21 \%$, two steps with two purifications) was higher than that of the $\mathbf{3} \rightarrow \mathbf{7}$ transformation (12\%, one purification).

Cyclic peptides of larger size and incorporating different amino acids were then prepared (Figure 1). The amino acid sequence of $\mathbf{8}$ (9 amino acid-cycle) reproduces most of the sequence of antibiotic tyrocidine, ${ }^{13}$ and 9 (12 amino acid-cycle) reproduces the loop sequence of an oxidoreductase (dihydrolipoamide dehydrogenase, UNiProtKb P09063). ${ }^{14} \mathbf{1 0}$ Was synthesized to assess whether histidine interferes with the thiol-maleimide reaction, since it has been described that $N$-terminal maleimido-derivatized, histidinecontaining peptides can easily undergo an intramolecular imidazole-maleimide Michael-type reaction. ${ }^{15}$ However, $N$-terminal maleimido-derivatized, histidine-containing peptides have been successfully used in conjugationswith thiol-derivatized oligonucleotides. ${ }^{16}$

\footnotetext{
${ }^{13}$ (13) Sieber, S. A.; Marahiel, M. A. J. Bacteriol. 2003, 185, 70367043

${ }^{14}$ (14) Li, W.; Liu, Z.; Lai, L. Biopolymers 1999, 49, 481-495.

15 (15) Papini, A.; Rudolph, S.; Siglmüller, G.; Musiol, H.-G.; Gohring, W.; Moroder, L. Int. J. Peptide Protein Res. 1992, 39, 348355 .

${ }^{16}$ (16) Ming, X.; Alam, M. R.; Fisher, M.; Yan, Y.; Chen, X.; Juliano, R. L. Nucleic Acids Res. 2010, 38, 6567-6576.
}

Cyclic peptides $\mathbf{8}$ and $\mathbf{9}$ were prepared by attaching $\mathbf{2}$ to the peptide-resin. Compound 11 (Figure 1, ref. 11), in which the protected maleimide moiety is linked to the side chain of lysine, was used for the synthesis of $\mathbf{1 0}$. In all cases solid-phase assembly was first followed by an acidolytic treatment to remove protecting groups on the peptide chain, and after purification the retro-DielsAlder reaction that deprotects the maleimide was carried out. As in the case of $\mathbf{7}$, the latter was accompanied by cyclization, as assessed by reaction with $\mathrm{H}_{2} \mathrm{O}_{2}$. These experiments showed that the thiol-maleimide reaction provides peptide cycles with at least 12 amino acids with very good [maleimide deprotection+cyclization] yields ( $\sim 50 \%$ ), both with head-to-side chain and side chain-toside chain linkages, and including a variety of trifunctional amino acids. They also showed that histidine-containing peptides can be cyclized making use of the Michael-type reaction even if the histidine residue is very close to the maleimide unit. In agreement with other authors' results, ${ }^{8}$ cyclic peptides were found to elute before the linear precursors upon HPLC analysis.

Figure 1. Structures of cyclic peptides 8-10, and of the lysine derivative 11 used in the synthesis of 10,14 and 17).



To further explore the scope of the method two bicyclic peptides, 14 and 17 (Scheme 2), were synthesized. In the former ("spectacles-like") the two cycles are separated by two residues of the peptide chain, while in the latter the cycles have part of the chain in common. For their preparation we combined 3maleimidopropanoic acid (1), the lysine derivative 11, and two orthogonally protected cysteine residues, 
$\mathrm{Cys}(\mathrm{Trt})$ and $\mathrm{Cys}(\mathrm{S}-t \mathrm{Bu})$. Since $\mathbf{1}$ can only be installed at the $N$-terminal (see above), by adequately placing the other three residues either type of bicycle can be obtained.

Trifluoroacetic acid treatment of peptide-resins 12 and 15 removed all protecting groups except those of $\mathrm{Cys}(S$ $\mathrm{tBu}$ ) and the maleimido-derivatized lysine, so that reaction between the $N$-terminal maleimide and the free thiol furnished the first cycle (compounds $\mathbf{1 3}$ and 16, respectively). The $\mathrm{S}-t \mathrm{Bu}$ group was subsequently removed from the still protected cysteine residue by reaction with tris(carboxyethyl)phosphine. After purification to remove excess phosphine and prevent reaction between the phosphine and the maleimide, ${ }^{10}$ heating in a microwave oven deprotected the maleimide attached to the lysine side chain and promoted the second cyclization. In both cases the target bicycle (14 or 17) was obtained. With this sequence of steps it is not possible to prevent formation of oligomeric cyclic peptides during the first cyclization.

Scheme 2. Synthesis of bicyclic peptides with either two peptide-linked rings (a), or two cycles with shared amino acids (b).

a)



b)

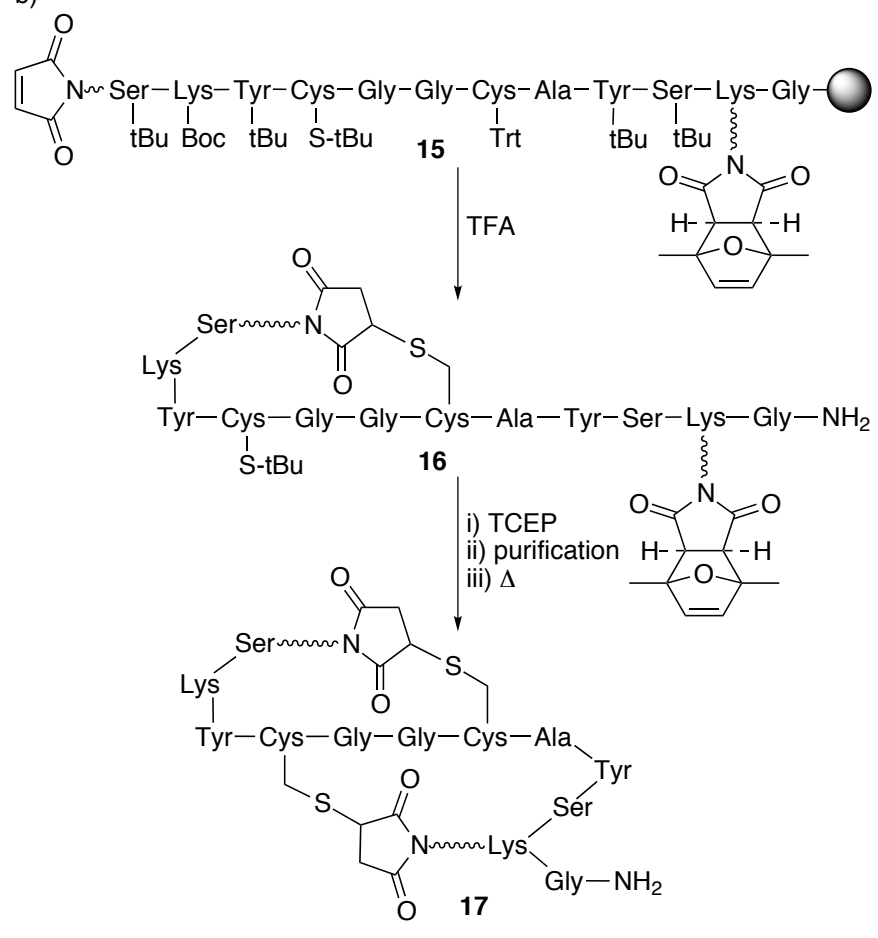

In summary, the Michael-type thiol-maleimide reaction is a straightforward procedure for the synthesis of cyclic peptides. If the peptide is appended with a free maleimide, cyclization takes place during the acidpromoted removal of peptide protecting groups, and formation of some cyclic dimers and trimers cannot be fully avoided. In case the peptide is derivatized with a 2,5-dimethylfuran-protected maleimide, which can be placed anywhere in the sequence, cyclization and maleimide deprotection take place simultaneously and in good yield, and formation of oligomers can be kept to a much lower extent. The method has proved suitable to synthesize up to 43 -membered rings. It is compatible with most trifunctional amino acids, namely those bearing hydroxyl, acid and basic functional groups.

An adequate choice of the protection scheme allowed structurally different bicyclic peptides, with the two rings fused or isolated, to be obtained. For this purpose peptide chain precursors incorporated two differently protected cysteines, a free maleimide and a protected maleimide.

Acknowledgments. This work was supported by funds from the Ministerio de Economía $y$ Competitividad (grants CTQ2007-68014-C02-01 and CTQ2010-21567-C02-01, and the project RNAREG, grant CSD2009-00080, funded under the programme CONSOLIDER INGENIO 2010), and the Generalitat de Catalunya (2009SGR-208). X. E. was a recipient fellow of the MINECO.

Supporting Information Available. Experimental procedures, compound characterization data and spectra, and HPLC profiles. This material is available free of charge via the Internet at http://pubc.acs.org. 